\title{
Spiritual interventions in psychotherapy: Evaluations by highly religious clients
}

Jennifer S. Martinez

Brigham Young University

Timothy B. Smith

Brigham Young University, tbs@byu.edu

Sally $\mathrm{H}$. Barlow

Brigham Young University, sally_barlow@byu.edu

Follow this and additional works at: https://scholarsarchive.byu.edu/facpub

Part of the Counseling Psychology Commons, and the Religion Commons

\section{Original Publication Citation}

Martinez, J. S., Smith, T. B., \& Barlow, S. H. (2007). Spiritual interventions in psychotherapy: Evaluations by highly religious clients. Journal of Clinical Psychology, 63, 943-960.

\section{BYU ScholarsArchive Citation}

Martinez, Jennifer S.; Smith, Timothy B.; and Barlow, Sally H., "Spiritual interventions in psychotherapy: Evaluations by highly religious clients" (2007). Faculty Publications. 2025.

https://scholarsarchive.byu.edu/facpub/2025 


\section{Running Head: RELIGIOUS INTERVENTIONS}

Martinez, J. S., Smith, T. B., \& Barlow, S. H. (2007). Spiritual interventions in psychotherapy: Evaluations by highly religious clients. Journal of Clinical Psychology, 63, 943-960.

Spiritual Interventions in Psychotherapy:

Evaluations by Highly Religious Clients

Jennifer S. Martinez, Timothy B. Smith, and Sally H. Barlow

Brigham Young University 


\begin{abstract}
Spiritual and religious interventions in psychotherapy have increasingly received research attention, particularly with highly religious clients. This study examined client opinions about and experiences with religious interventions in psychotherapy. A sample of 152 clients at a counseling center of a university sponsored by the Church of Jesus Christ of Latter-day Saints (LDS) completed a survey with ratings of specific religious interventions with regards to appropriateness, helpfulness, and prevalence. Out-of-session religious interventions were considered more appropriate by clients than in-session religious interventions, but in-session interventions were rated as more helpful. Specific interventions considered both appropriate and helpful by the LDS participants included referencing scriptural passages, teaching spiritual concepts, encouraging forgiveness, involving religious community resources, and conducting assessments of client spirituality. Some religious interventions were perceived as inappropriate or not helpful, and clients provided explanations for why religious interventions can be either effective or ineffective in psychotherapy.
\end{abstract}


Religious Interventions in Psychotherapy:

Evaluations by Clients at a Private Religious University

Research has consistently documented the prevalence of religious beliefs and affiliation in North America (e.g., Hoge, 1996; Keller, 2000), with recent estimates indicating that over 80\% of Americans consider themselves affiliated with a religion and that over $75 \%$ affirm the absolute existence of God and pray at least weekly (Baylor University, 2005). In recent decades, psychologists have increasingly recognized the need to address spiritual and religious issues in mental health treatment, particularly when working with highly religious clients (Hage, 2006; Richards \& Bergin, 2005). Psychologists generally appear to be open to values and practices traditionally associated with religion (Crook-Lyon, O’Grady, Smith, Jensen \& Golightly, 2007; Shafranske, 2000; Walker, Gorsuch, \& Tan, 2004), and the mental health literature increasingly documents ways in which religiousness may be effectively integrated within interventions and psychotherapy (Miller, 2003; Pargament, 1997; Shafranske, 1996; Smith, Bartz, \& Richards, in press; Wade, Worthington, \& Vogel, 2007). The field can now benefit from increased understanding about why religious interventions may or may not be effective and about which particular interventions are most appropriate and helpful with clients who already endorse or seek to address spiritual and religious issues in therapy.

Religiousness has often been defined as adherence to an institutionalized system of beliefs, values, and activities based upon spiritual creeds, whereas spirituality refers to transcendent experiences and understandings about God and/or other non-visible characteristics of life and the universe (Kelly, 1995). Individuals can be both spiritual and religious, primarily religious but not particularly spiritual, or primarily spiritual but not religious. Many of the interventions in psychotherapy examined in this manuscript (e.g., prayer, encouraging forgiveness) have both spiritual and religious components. Nevertheless, because most of the 
interventions we investigated have explicit religious foundations (e.g., scripture reading), we will use the term religious throughout this manuscript unless the context warrants specification.

Clients in psychotherapy often grapple not only with issues of wellbeing but also with their perspectives on life, their relationships with others, and their deepest values. For many clients, religious issues intertwine with these concerns (Smith \& Richards, 2005). In those circumstances, clients may benefit from explicitly addressing religious themes in therapy or by drawing upon religious resources to supplement other therapeutic methods of coping. Just as adaptations to psychotherapy that account for client's cultural values and experiences can greatly enhance the efficacy of treatment (Griner \& Smith, 2006), adaptations to psychotherapy for clients who strongly endorse religion may enhance the efficacy of treatment (Richards, Keller, \& Smith, 2004; Smith et al., in press). Moreover, psychologists have an ethical obligation to provide services that address client contexts, including religious contexts (APA, 2002).

Psychotherapists particularly need to account for the experiences and beliefs of clients who strongly endorse religion. Accurate understanding of clients' religious views can positively impact treatment, while ignoring religious beliefs may reduce therapy efficacy and increase premature client termination (Miller, 2003, Propst, 1980; Smith \& Richards, 2005). Specifically, highly religious individuals often fear that their values, ideas, or conduct may not be endorsed by clinicians (Worthington, 1986), so they may avoid therapy or seek out mental health professionals whom they believe will share their beliefs (Worthington, Dupont, Berry \& Duncan, 1988). Highly religious individuals are the most likely to desire the integration of religious interventions in therapy. Hence, study of religious interventions in therapy seems particularly warranted among populations who already strongly endorse religious values.

As has been widely documented in the literature, the inclusion of religious issues in psychotherapy creates the potential for several ethical dilemmas to arise (Richards \& Bergin, 
2005). Considerations regarding informed consent (Hawkins \& Bullock, 1995), religious/spiritual identity development (Fowler, 1991; Hood et al., 1996; Poll \& Smith, 2003), dual relationships (Sonne, 1999), collaboration with religious leaders (Chappelle, 2000), respect for clients’ values (Haug, 1998; Neusner, 1994), work setting boundaries (Chappelle, 2000; Richards \& Bergin, 2005), and therapist competence (Barnett \& Fiorentino, 2000; Lannert, 1991) are essential when deciding whether or not to use interventions based on religion. Recommendations in each of these areas have been offered in the literature, informing therapists about these potential problems and assisting them to practice psychotherapy ethically. However, understanding client perspectives about what factors impair the efficacy of religious interventions in therapy would also be important information for practitioners.

A wide variety of interventions that may be considered religious have been promoted in the literature, including praying with clients, discussing sacred writings, involving resources available in religious communities, engaging in spiritual meditation or religious rituals, and encouraging moralistic actions such as forgiveness (Richards \& Bergin, 2005). Although therapists may take different approaches to how they integrate these kinds of interventions (e.g., Worthington, 1986), they have been found to be effective across a variety of settings and do enhance the efficacy of therapy (Smith et al., in press). Religious interventions have been successfully integrated into traditional secular treatments such as cognitive behavioral therapy (Propst, 1980; Propst, Ostrom, Watkins, Dean \& Mashburn, 1992; Nielsen, Johnson, \& Ridley, 2000), psychoanalytic therapy (Rizzuto, 1996), transpersonal therapy (Vaughan et al., 1996), and marital therapy (Sperry \& Giblin, 1996). However, we currently know little about which religious interventions are the most effective or why they are effective with highly religious clients.

A few research studies have investigated the reported use of religious interventions by psychotherapists (Ball \& Goodyear, 1991; Jones, Watson, \& Wolfram, 1992; Moon et al., 1993; 
Richards \& Potts, 1995; Worthington et al., 1988). However, most of the available research evaluates the use of religious interventions from the perspective of clinicians. Although two previous studies report data regarding clients’ religious concerns (Johnson \& Hayes, 2003; Rose, Westefeld, \& Ansley, 2001), and another study reviewed client opinions regarding the helpfulness of religious interventions (Worthington et al., 1988), we were unable to locate any study of actual client experiences and perceptions regarding the appropriateness and helpfulness of religious interventions in their current treatment. Such information would appear to be essential to inform therapists in their integration of religious interventions into psychotherapy. Therefore, the current study attempted to answer the following questions: What religious interventions are perceived as most appropriate by highly religious clients? Which of those interventions are perceived as being most helpful? What are the reasons highly religious clients perceive religious interventions within therapy to be effective and ineffective?

\section{Method}

\section{Participants}

Participants were 152 university students receiving services at the counseling center of a large, private university sponsored by the Church of Jesus Christ of Latter-day Saints (LDS). Fifty-six (37\%) participants were male, and 96 (63\%) were female. Ages ranged from 18 to 37 years, with 62 (41\%) being 18-21, 71 (47\%) being 22-25, and 19 (12\%) being 26-37. All of the client participants, as well as all of the therapists at the counseling center, were members of the LDS Church. Participants reported permanent residency status across many states, but the most commonly reported were Utah (19\%), California (12\%), and Idaho (5\%); 10 participants were from outside the United States (7\%).

The counseling center provides free psychological services to full-time students of the university. No session limits are imposed, and in this study, 63 clients (41\%) had completed 1-4 
sessions, 31 clients (20\%) had completed 5-9 sessions, and 58 clients (38\%) had completed 10 or more sessions. The counseling center employs 27 licensed psychologists, 2 licensed marriage and family therapists, 4 psychology post-doctoral residents, 4 pre-doctoral psychology interns, and trains approximately 20 psychology doctoral students in part-time placements. The counseling center provides traditional mental health services consistent with those at other counseling centers across the U.S. and includes an APA-accredited internship program. Religious interventions are not standard practice, but because the counseling center serves predominantly LDS clients and the climate of the university fosters open discussion of LDS doctrines, several therapists at the center provide occasional religious interventions in the course of ongoing treatment.

No restrictions were placed on client diagnosis. Primary presenting problems varied among the respondents, with 53 (35\%) reporting depression, 20 (13\%) reporting anxiety, 20 (13\%) reporting relationship concerns, and the remaining 59 (39\%) reporting a variety of other conditions, including eating disorders, obsessive compulsive disorder, schizophrenia, sexual concerns, and general stage of life concerns. History of trauma or abuse was endorsed by 9 (6\%) clients. Spiritual or religious concerns were not endorsed as a primary concern by any respondent.

\section{Procedures}

Signs inviting clients to participate in a research survey were posted in the counseling center reception area. The counseling center serves approximately 750 clients at any given time, and data were collected over several weeks in March, 2004 and September, 2004. The topic of the survey was not disclosed in the advertisement to reduce the likelihood that clients would be biased in deciding whether or not to participate. Upon client request, reception staff provided them with a survey, statement of informed consent, and a large candy bar as a form of compensation for their time. Clients completed the survey in a private seating section of the 
reception area. All surveys delivered to clients were returned completed with the exception of six surveys that contained missing responses within the same section (appropriateness of religious interventions, described below) because their therapists had not utilized any religious interventions in therapy. With the exception of those missing items, all 152 surveys were included in the analyses.

\section{Survey Instrument}

The first page of the survey asked respondents to provide background and demographic information, including religious affiliation, age, gender, geographical origin, the number of sessions they have had with their current therapist, and the presenting concern(s) that initiated psychotherapy. Level of religiosity was assessed to verify that the participants in the study were on average highly religious, as intended. We used a single item asking the clients to rate how important their religion is to them on a 9-point Likert-type scale $(1=$ "Not at all" and $9=$ "Extremely important; My religious faith is the center of my entire life"). This question was previously found to correlate .84 with an "intrinsically pro-religious" factor derived from a multiple-item scale (Gorsuch, 1972); this correlation is approximately the same value as the median correlation (.76) that multiple-item measures of religiousness have with one another (see also Gorsuch, 1984). The mean score on the single item evaluating client religiosity was 8.2 (SD $=1.4$ ) on the 9-point scale, indicating extremely high endorsement of religious sentiment in this sample, as expected (Richards, 1994). Although 12 participants (8\%) scored less than 7 on the 9-point scale (indicating less than very high levels of personal religious devotion), these participants were not excluded from the analyses because we assumed that (a) very high levels of religious devotion were relevant but not requisite for religious interventions to be integrated into therapy, (b) individual variation in personal devotion would occur among members of any group, and (c) it was important to represent the experiences of all clients who participated in the survey. 
On the second page of the survey, clients indicated whether 18 distinct religious interventions have been used with them in therapy. The list of interventions was created by Richards and Potts (1995), who derived their list and definitions of religious interventions from clinician responses gathered by Ball and Goodyear (1991). Although the religious interventions evaluated in the current study are not an exhaustive list of all of those that might be incorporated in psychotherapy, the list does represent the most commonly implemented religious interventions and our procedure allowed for comparisons with previous research regarding therapist opinions. Richards and Potts had divided the 18 interventions into two categories of 9 "in-session" and 9 "out-of-session" religious interventions, based on where the intervention was more likely to occur. Our survey provided definitions for each intervention so that clients would consistently understand the meaning of the terminology.

The third page of the survey asked respondents about the perceived helpfulness of any of the 18 religious interventions that they endorsed on page two as being used by their therapist. Interventions were rated on a 6-point Likert-type scale $(0=$ Very Unhelpful, $1=$ Moderately Unhelpful, 2 = Somewhat Unhelpful, 3 = Somewhat Helpful, 4 = Moderately Helpful, and 5 = Very Helpful). Similarly, the fourth page of the survey asked respondents to rate on a 6-point Likert-type scale how appropriate they feel it is for therapists to use each of the 18 religious interventions $(0$ = Highly Inappropriate, 1 = Moderately Inappropriate, 2 = Somewhat Inappropriate, 3 = Somewhat Appropriate, 4 = Moderately Appropriate, and 5 = Highly Appropriate).

On the fifth page, respondents were asked to recall when a religious intervention was particularly effective in helping them grow or change, and to write briefly about their experience. The sixth page was identical, except respondents were asked to describe when a religious intervention was particularly ineffective. 
Participants’ written responses to the open-ended questions on the last two pages of the survey were analyzed using established methods for content analysis (Denzin \& Lincoln, 2000). Responses provided by participants were first typed and then read in their entirety several times to obtain an overall sense of their content. Meaningful content units within the responses were then identified and highlighted. Subsequently, content categorization was performed by first reading a response and then by generating a working definition and preliminary category name that reflected the intended meaning of the participant. Each successive response was then read and either added to an existing category or placed into a new one. This process of sorting responses into categories continued until all responses had been assigned a category. Each category was then given a formal title and description. The categorization process was repeated a second time, this time guided by the explicit titles and descriptions generated in the initial round. Although the results were very similar, a few responses were placed in different categories based on the definitions/titles that were now available. The results of the second round of analysis were then given to an independent rater who assessed the categories for conceptual clarity and distinctiveness, examined the participants’ responses for additional meaning that was not included in the existing categories, and verified the overall accuracy of the coding. The raters resolved coding discrepancies by reviewing transcripts until consensus was achieved.

\section{Results}

\section{Reported Appropriateness}

Mean scores and standard deviations of clients’ ratings of perceived appropriateness of the 18 interventions are displayed in Table 1. The in-session religious interventions that were considered most appropriate by respondents were reference to scripture, therapist private prayer, and therapist teaching religious/spiritual concepts. The out-of-session religious interventions that were considered most appropriate were encouraging forgiveness, consulting religious community 
members to facilitate treatment, religious journaling, and encouraging client private prayer. Blessings by the therapist (laying on of hands) and therapist-client prayer were in-session interventions considered least appropriate by these respondents. The out-of-session intervention that was considered least appropriate by these respondents was scripture memorization. Overall, client ratings of appropriateness of out-of-session interventions $(M=33.7)$ were significantly higher $\left(t_{(144)}=10.4, p<.01\right.$, Cohen's $\left.d=.65\right)$ than in-session interventions $(M=28.3)$.

\section{Reported Helpfulness}

Clients rated the helpfulness of those religious interventions which had actually been used by their therapist. A summary of the means and standard deviations of these ratings can be found in Table 1. The number of ratings for each intervention corresponds with the number of religious interventions actually experienced by clients, rather than the total number of participants. This contingency data created few responses for those interventions that were infrequently used, as reported in Table 1.

The religious interventions rated most helpful by clients who had experienced them were: teaching religious concepts, religious/spiritual self-disclosure of the therapist, encouraging clients to forgive others, assessing client religiousness, and citing passages of scripture. The religious interventions that clients rated least helpful included: scripture memorization, referral for a priesthood blessing, therapist and client prayer together, therapist encouraging client confession, therapist prayer, and blessing by the therapist. It should be noted that religious interventions which were rated most helpful by clients were those that had the highest prevalence rates, meaning that the interventions perceived to be the most helpful apparently occurred with greater frequency in therapy. Therapists appeared to be using the most helpful religious interventions more often than those perceived by clients to be less helpful. 
The average rating of perceived helpfulness across all religious interventions was 3.3, which fell between the "somewhat helpful" and "moderately helpful" anchors. Helpfulness scores for each client were also summed according to in-session and out-of-session interventions. Contingency data prevented the use of a paired sample $t$-test because clients who did not rate at least one intervention in each category would be eliminated (leaving no participants in the analysis). Nevertheless, the overall mean of in-session helpful ratings $(M=3.50)$ was notably higher (standardized mean difference Cohen's $d=.47$ ) than the overall mean of out-of-session helpfulness ratings $(M=2.94)$.

As seen in Table 1, correlations between clients' ratings of helpfulness and appropriateness were generally of high magnitude for in-session interventions. However, even though clients perceived therapists’ engaging in private prayer as appropriate, they did not perceive this practice as helpful (as would be expected because any therapist private prayers would not be audible in session). When compared with the correlations obtained for in-session interventions, the correlations obtained for out-of-session interventions were notably smaller. Typically, correlations between clients' perceptions of helpfulness and appropriateness of out-ofsession interventions were of small to moderate magnitude. There was no correspondence between these ratings for clients who were referred by therapists to ecclesiastical leaders for a priesthood blessing, and there was an inverse relationship between perceived helpfulness and appropriateness ratings among clients who were encouraged by a therapist to confess sins to an ecclesiastical leader. Hence, clients who may have felt that confession was appropriate tended to find that particular intervention unhelpful.

Qualitative Analyses Regarding Effective and Ineffective Interventions

We also analyzed written responses by participants to two questions concerning situations when they perceived religious interventions to be effective and ineffective. In response to the 
open-ended question about effective interventions, 125 (82\%) participants provided responses, but only 56 (37\%) provided responses to the open-ended question regarding ineffective religious interventions. Written responses for 26 cases contained descriptions of interventions outside of therapy (i.e., by ecclesiastical leaders) and were excluded from analysis because we were only interested in interventions provided in mental health settings. Upon further examination of the data, we noted that several responses to the "effective” question actually reflected experiences or opinions regarding what the respondents considered ineffective, and vice versa. Therefore, in our coding of the data, we analyzed the statements according to their content, rather than strictly according to which question was being asked. In addition, we found that 40 responses across both questions were general statements about religious interventions without an evaluation of efficacy. Hence, final coding of the qualitative data involved three distinct content areas: reasons why religious interventions were considered effective, reasons why religious interventions were considered ineffective, and neutral comments regarding religious interventions.

\section{Reasons Why Interventions Were Effective}

Participants' reasons for why they perceived religious interventions to be effective were coded into six categories (Table 2). Direct quotations that exemplify these categories are provided in the following paragraphs.

Increased insight; reframed perceptions. By far the most common reason cited by clients for why religious interventions were effective for them involved increased insight or reframed perceptions. Addressing issues from a religious viewpoint led clients to experience new understandings about their condition. 
scripture and thought have been very helpful to me, and I have quoted it to myself several times since then. I suppose it is a simple thought, but it really does give me hope and encouragement.

My therapist asked me how important my religion was to me. Because it is the center of my life, I realized I needed to make changes now to affect my future in a positive way.

Regardless of the specific technique that the therapist used (i.e., teaching doctrine/scripture, confrontation, or assessment questions), the common perceived benefit was that clients gained a new perspective/awareness about themselves or about their problems that facilitated growth. Increased comfort from value congruency with the therapist. Distinct from the primarily cognitive flavor of responses just described, other client responses tended to emphasize relational or emotional components. Several client responses highlighted the positive emotional effects from sharing similar faith/values with the therapist (value congruency). For these clients, simply being aware that their therapist shared similar values or religious beliefs increased their personal comfort, confidence, and openness in therapy.

All that mattered to me as a client was to know my therapist was familiar with my religious beliefs. Them being a member [of my church] brought me a sense of comfort and understanding.

I have no problem when my therapist cites scriptural references, religious leaders, or spiritual topics - in fact it helps me to feel more comfortable talking with my therapist. I'm able to open up more, because I know he understands me on another level, and also because I don't have to restrict my vocabulary or avoid religious topics that might make my relationship less comfortable as it might with another (secular) therapist.

When therapists discussed religious issues within these clients' vernacular, they demonstrated sensitivity to the clients that enhanced the therapeutic relationship.

Increased recognition of spiritual realities/influences. Other clients discussed how religious interventions in therapy helped them to recognize transcendent influences across other 
circumstances/situations. Simply inviting religious influences to be discussed as part of therapy resulted in clients' enhanced awareness of feelings about God, circumstances attributed to divine intervention, being "touched by the Spirit," etc. A representative quotation is: "Hearing her [my therapist's] perspective helped me to feel the Holy Ghost which brought much needed peace.” Discussing religious/spiritual issues in sessions may also enhance a client's ability to experience a personal connection with a Higher Power that enables positive change:

I have been quite angry at God for abuse that has happened in my life, and by helping me to realize the importance of agency and that God does love me, it has helped me to use a spiritual connection to heal, instead of shutting off that source and trying to do everything on my own.

Because religious interventions are based on the assumption of transcendent realities, such as the existence of Deity, it follows that clients would express being influenced by that Deity. The influence of Deity as a result of religious interventions in therapy was clearly a perception expressed by these clients.

Increased sense of empathy/connection from the therapist. An emotional benefit described by clients involved increased perceptions of the therapist's concern for them as an individual. Religious interventions helped them feel loved, such as "I know they care and know me well if they take spirituality into consideration.” These clients considered their therapist's use of religious interventions as a demonstration of love or concern.

Increased credibility of therapy. For some apparently skeptical clients, the inclusion of religious interventions increased their positive perceptions of therapy in general. The religious interventions provided in session not only addressed a particular issue experienced by the client but had an overall effect to increase the client's trust in the therapy process. 
Because he [the therapist] coupled his words with scripture, and helped me see how to simply live more fully those concepts I already believed, I was able to trust him by transferring the trust I already had with respect to my faith, religion, scriptures, etc. onto him.

In therapy my counselor used some references to scriptures. For me this was especially effective because I study \& believe the scriptures \& it added an external validation to what I often perceive as the 'stuff \& rot' of psychology.

For these clients, religious interventions enhanced the credibility of the therapist and resulted in increased client engagement in therapy.

Religious interventions addressed the client's “whole self." Several clients noted that including religious issues in psychotherapy allowed for a more comprehensive approach to treatment: "In learning about my spiritual and religious convictions he [my therapist] was able to better and more fully assess my problem" and "I felt it was more of a full effort to improve all parts, not just psychological but spiritual as well.” Addressing religion was considered necessary for change by some clients who view this aspect of their lives as extremely important to them: "My religion drives everything I do; they must counsel me on that to help me change the core person I am.”

Because my religious beliefs are so important to me, and guide my life, it seems natural that those beliefs should be a part of my experience in counseling. Many of my choices, decisions, and perspectives revolve around my spiritual beliefs.

Addressing religion was viewed by some clients as necessary in order to accurately reflect their “whole self” and therefore have a more meaningful experience in psychotherapy.

Reasons Why Religious Interventions Were Ineffective

Clients also reported several ways in which religious interventions were ineffective. Four major themes were extracted from these responses (Table 2). 
Ineffective delivery of the intervention. A variety of difficulties in the way therapists delivered religious interventions were cited. Some clients reported that therapists had been condescending or offensive in their attempts to integrate religious content into therapy: "It almost feels like being talked down to” and “The counselor wouldn’t respect [my] feelings and was trying to explain how God could help me, and it offended me." Simplistic recommendations were also problematic for clients: "Just saying that I could overcome a weakness with prayer and scripture study was ineffective and frustrating.” Sometimes therapists provided too much information: "I recall a time when too much scriptural references were made and I zoned out because I was not prepared to absorb all the information provided.” Other times therapists provided too little information, citing general principles with "no specific plan" or concrete applications. Other clients indicated that religious interventions were ineffective due to their own level of readiness not matching the timing of the intervention.

I don’t feel like any religious techniques have ever been ineffective because of the technique in and of itself. When things have been ineffective I feel that it is because I was not in the right mindset or was unwilling to put a sincere effort forth.

Timing and receptivity are clearly considerations when deciding whether to use a religious intervention with a particular client.

Increased feelings of anxiety or guilt. Negative experiences with religious interventions occurred when client anxiety or guilt was evoked. This anxiety or guilt was associated either with not following through with the recommended intervention or with being reminded about shortcomings or "faults."

Spiritual techniques have always been effective for me though sometimes if I am reminded of a scripture she tells me, I feel guilty for not following it perfectly, hence guilty, therefore feeling more pressure to have to be more perfect. 
I received a list of scriptural references relating to anxiety, and I was instructed to read and consider these scriptures. I'm sorry to say that I did not read these scriptures due to my lack of time. Thus, this actually heightened my anxiety rather than subsiding it.

Religious interventions can be detrimental when clients associate them with judgmental attitudes and other anxiety- and guilt-provoking situations. This might particularly be the case when clients have a previous history of anxiety or when they do not follow through with recommendations (an indication of discomfort with the intervention).

Inappropriate therapist role to act as an ecclesiastical leader. Some respondents expressed the idea that providing religious interventions in therapy crosses role boundaries between professional and ecclesiastical responsibilities. Clients who affirmed a necessary separation between the role of therapist and ecclesiastical leader made comments like "I don’t find it appropriate for a counselor to assume role of a bishop" and "My opinion is religion can be talked about but not used so much to influence. That's up to bishops or parents but counseling...should stay professional.” These respondents made explicit their discomfort with possibly conflicting roles.

Inappropriate to include spiritual interventions in therapy. Even though the clients participating in this study were on average highly religious, several participants expressed the opinion that religious interventions were ineffective because psychotherapy was simply an inappropriate venue for them. They felt that psychotherapy should not deal with religious doctrines: “I’ve never had a spiritually positive experience in counseling. It always seems to be an inappropriate situation for it” and "Spiritual therapy probably shouldn’t be mixed with psychotherapy.” These clients preferred a clear distinction between psychological interventions and religious interventions, which were seen as inappropriate for mental health settings. 


\section{Neutral Comments about Religious Interventions}

As previously mentioned, 40 clients gave written responses that did not provide reasons why religious interventions were effective/ineffective. These responses tended to provide generic comments or advice regarding ideal conditions for using religious interventions in psychotherapy. These responses were subsequently collapsed across three categories described below.

Allow client to initiate religious/spiritual themes. Seventeen respondents expressed opinions that clients should be allowed to bring up religious or spiritual issues—but that therapists should not engage in extensive discussions unless the clients initiates the topic. This sentiment was expressed primarily through reports of satisfaction of therapists who did wait for their clients to bring up religious issues before addressing them in therapy.

He [the therapist] never brought up religion. I was the one who initiated such talk, and such discussion usually dealt with feelings of obligations and guilt . . . and he helped me gain perspective (I am not a bad person for missing church, etc.) and such discussions have been the extent of our religious talk in sessions. Other than that, religion would not have been appropriate, and for me, even detrimental.

These clients wanted therapists to be willing to address religious issues when they bring up the issue and to discuss them in ways that are congruent with their own worldviews. They did not want to feel "forced" to address religious issues.

The appropriateness of religious interventions depends upon the treatment goals. Seventeen participants indicated that religious interventions should be related to treatment goals. Their use should match the client's values, and how they are implemented should vary for each client: "I find nothing wrong with religious techniques PROVIDED they are pertinent to the client's progress" and "Religion...is only as useful as we make it. It has to be incorporated in an appropriate way for each client and according to the client's value for this technique.” These 
responses suggest that therapists tailor their use of religious interventions to the needs of each individual client.

More religious interventions were desirable. A final set of comments made by six clients were characterized by a desire for therapists to use more religious interventions with them in the future. For example, "I feel I could have good experiences if he [the therapist] talked about spiritual things more” and "I have not received many spiritual therapies. I sort of wish that I had received more, and that I will in the future.”

\section{Discussion}

In therapy at a counseling center of a religiously-affiliated university, clients in this study endorsed several religious interventions as being appropriate and helpful. Some clients expressed a desire for religious interventions to be more integrated into their treatment, but the prevalence rates of specific religious interventions reported by clients in the current study approximate the results found in previous research involving therapists’ estimates (Moon et al., 1993; Richards \& Potts, 1995; Worthington et al., 1988).

Regarding clients’ perceived appropriateness of religious interventions in psychotherapy, out-of-session interventions were considered more appropriate than in-session interventions. Nevertheless, in-session interventions tended to be rated as more helpful. Out-of-session religious interventions may be considered less invasive or less threatening than in-session interventions, which are completed in the presence of the therapist. However, it should also be noted that out-of-session interventions were used less than half as often as in-session interventions, with only 148 total reported out-of-session interventions used, and 299 total reported in-session interventions used. The relative under-utilization of out-of-session religious interventions by therapists may have several explanations that could be further evaluated in future research, if this pattern holds across other settings with other samples. 
This particular sample of LDS clients found several religious interventions to be moderately helpful when included in psychotherapy. Those found to be most helpful were: therapists teaching religious/spiritual principles, therapist self-disclosure about religious/spiritual issues, therapist encouraging client forgiveness of others, therapist assessing client religiousness/spirituality, and therapist references to scripture. These results overlap somewhat with those found by Worthington et al. (1988), including encouragement to forgive others or God and religiously-oriented homework. They are also similar to the perceptions of therapists (Richards \& Potts, 1995), who listed teaching spiritual concepts, use of religious community, and reference to scripture as being the most helpful supports to clients. It should also be noted that in the current study the most helpful interventions were also rated as some of the most appropriate and most used by these clients. Thus, it appears that therapists in the current study were generally using religious interventions that were perceived as helpful by their clients. However, in some cases, clients were mixed in their ratings (such that the same intervention was seen by some clients as helpful and by some clients as unhelpful), which suggests that features other than the specific intervention may be responsible for the perceived effectiveness. Previous literature has suggested that elements such as client variables, therapist variables, and process variables contribute more to the effectiveness of an intervention than the intervention itself (Bergin \& Garfield, 1994).

Content analysis of the open-ended questions obtained by clients in the current study provided themes for the reasons why religious interventions were perceived to be effective and ineffective. Overall, these responses reflected a significant overlap between general counseling competence and competence in the use of religious interventions. For example, clients generally focused on factors such as gaining new perspectives, feeling positive regard from their therapist, and addressing the needs of the client, rather than on specific religious interventions, when citing 
reasons that religious interventions may be effective. Similarly, clients generally focused on factors such as ineffective delivery when citing reasons for ineffective experiences with religious interventions in therapy. Given these results, it would not be surprising if future research were to verify that the enhanced outcomes associated with religious interventions (Smith et al., in press) are due to general factors impacting the therapeutic alliance and client expectations as much as the impact of the intervention itself.

In response to the two open-ended questions about effective and ineffective religious interventions, clients in this study did list twice as many instances when the interventions were effective vs. ineffective. They also reported a variety of positive cognitive and emotional effects that came from the use of religious interventions. For example, several clients indicated that they felt increased comfort and trust with someone who generally shared their religious beliefs and values, a finding that has been consistent across previous research (e.g., Bergin \& Jensen, 1990). However, a finding that has not been particularly mentioned in previous research studies is that several clients in the current study found that addressing religious issues in treatment promoted transcendent experiences, such as feeling God's influence in their lives. Psychologists have typically avoided or minimized experiences that are not observable (Bergin, 1980; 1991), but the decision to avoid transcendent experiences might not be justifiable given that other (nonreligious) psychological variables are also based exclusively upon participant perceptions. Future inquiry may benefit from improved understanding of transcendent experiences from client perspectives.

Even though instances of effective religious interventions were described with greater frequency than ineffective instances, the fact that 37 clients reported ineffective interventions is also essential to consider. Consistent with Chappelle's (2000) emphasis on therapists not imposing their values, clients in this study preferred therapists to follow their lead in discussing 
religious issues. Clients' descriptions of other ineffective aspects of religious interventions closely paralleled concerns frequently addressed in the professional literature about the context of therapy and the nature of the therapeutic relationship (Richards \& Bergin, 2005), such as concerns about therapists acting in an ecclesiastical role or about the timing of religious interventions. Such warnings are consistent with the findings of Worthington and colleagues (1988), who reported that the timing of an intervention was more important to effective therapy than the number of spiritual interventions used by a therapist. Clients with heightened anxiety or injurious previous experiences with religion were also quick to point out that for them, the very introduction of religious issues raises negative connotations, particularly feelings of guilt about their own inadequacies. Furthermore, some clients believed that psychotherapy is an inappropriate setting to discuss religious issues, regardless of considerations to the contrary. Hence, religious interventions should not be used as a matter of course, even in clinics ostensibly associated with a religious organization, without explicit client consent.

Sometimes clients perceived religious interventions in psychotherapy to be ineffective because of difficulties with delivery (e.g., miscommunication). Previous studies have indicated that a minority of clinicians express confidence and competence in integrating religious issues in psychotherapy (Shafranske \& Malony, 1990; Young, Cashwell, Wiggins-Frame, \& Belaire, 2002). Doctoral training programs do not adequately address religious issues (Brawer et al., 2002; Tan \& Jones, 1991; Walker et al., 2004), and this lack of training may lead therapists to avoid such issues, overcompensate for their lack of training by becoming excessively preoccupied with such issues, or ineffectively deliver religious interventions when they make the attempt. We join with other scholars in recommending that the field seriously consider issues of professional training regarding religious and spiritual interventions (e.g., Crook-Lyon et al., 2007; Young, Cashwell, \& Wiggins-Frame, 2007). 


\section{Limitations of the Study}

Several limitations qualify the results of this study. First, even though the participants were diverse with respect to age, gender, geographical origin, and presenting problem, they were a relatively homogeneous group of LDS college students. Although the results obtained do not differ substantively from those found elsewhere (Moon et al., 1993; Worthington et al., 1988), our data do not represent the experiences of individuals from other religious denominations or with other educational backgrounds. Furthermore, this study investigated therapy as conducted in a counseling center at a university sponsored by the LDS Church, so the results do not represent practices across other treatment settings. Because of the religious homogeneity of the university, therapists in the current study may have been more comfortable addressing religious issues openly with clients than therapists in settings characterized by denominational diversity, where there would be a clear need to take an ecumenical approach. Nevertheless, Bergin and Payne (1991) have affirmed that denominationally specific research can inform the field, and we urge comparative studies to be conducted with other populations and across other settings. Future research should continue to evaluate client perspectives on the uses and helpfulness of religious interventions in psychotherapy, particularly when clients, including $26 \%$ of university student clients, report moderate to extreme distress resulting from religious or spiritual problems (Johnson \& Hayes, 2003).

The use of self-report as the sole method of data collection is another potential limitation to the current study. We could not evaluate possible discrepancies between reported use and actual use of religious interventions, and the results are subject to possible monooperationalization bias (Cook \& Campbell, 1979). We also failed to evaluate changes in client symptomatology or wellbeing as a function of the interventions provided. Furthermore, the religious interventions were not standardized (manualized) across therapists, so there might have 
been variability in how each intervention was handled across cases. Finally, because not all clients who presented at the counseling center requested to participate in the survey, the participants in the study may have differed from non-participants in ways that may have biased the findings (e.g., participants may have been more motivated or more compliant than nonparticipants, which may reflect underlying differences in depressive symptoms or in willingness to challenge social conventions including religious norms, etc.).

\section{Summary}

Responding to a gap in the current literature (Chamberlain, 1996; Richards \& Bergin, 2005; Richards \& Potts, 1995), this study evaluated client perspectives regarding the appropriateness and helpfulness of religious interventions in psychotherapy. The study confirmed that religious (LDS) clients generally perceive religious interventions as appropriate and helpful in psychotherapy. However, there are some important qualifications that therapists must consider. When implemented, any religious intervention should clearly match client values, readiness, and reason for seeking therapy. Clients want to be supported and not manipulated. As with every other type of therapeutic intervention, therapists should carefully assess and be guided by client perspectives and preferences.

The data presented here regarding client perspectives and preferences regarding religious interventions should inform future outcome studies (Worthington \& Sandage, 2002). Existing psychotherapy outcome studies suggest that religious interventions are indeed more effective with religious clients compared to secular treatments (Smith et al., in press), but the next step for researchers is to make more headway in understanding the processes whereby religious interventions ameliorate client symptoms. The current study seems to underscore the salience of increased insight and reframed understandings brought about by the addition of religious perspectives, with relational and emotional benefits also apparent. Client attributions to 
transcendent experiences (e.g., feelings of closeness to Diety) also require exploration.

Psychotherapy process research that explicitly examines these issues can become a stronger focus of future research efforts. 


\section{References}

American Psychological Association (2002). Ethical principles of psychologists and code of conduct. American Psychologist, 57, 1060-1073.

Ball, R. A., \& Goodyear, R. K. (1991). Self-reported professional practices of Christian psychologists. Journal of Psychology and Christianity, 10, 144-153.

Barnett, J. E., \& Fiorentino, N. (2000). Spirituality and religion: Clinical and ethical issues for psychotherapists. Part II. Psychological Bulletin, 35, 32-35.

Baylor University. (2005). The Baylor religion survey. Waco, TX: Baylor Institute for Studies of Religion.

Bergin, A. E. (1991). Values and religious issues in psychotherapy and mental health. American Psychologist, 46, 394-403.

Bergin, A. E., \& Garfield, S. L. (Eds.). (1994). Handbook of psychotherapy and behavior change ( $4^{\text {th }}$ ed.). New York: Wiley.

Bergin, A. E., \& Jensen, J. P. (1990). Religiosity of psychotherapists: A national survey. Psychotherapy, 27, 3-7.

Bergin, A. E., \& Payne, I. R. (1991). Proposed agenda for a spiritual strategy in personality and psychotherapy. Journal of Psychology and Christianity, 10, 197-210.

Brawer, P. A., Handal, P. J., Fabricatore, A. N., Roberts, R., \& Wajda-Johnson, V. A. (2002). Training and education in religion/spirituality within APA-accredited clinical psychology programs. Professional Psychology: Research and Practice, 33, 203-206.

Chappelle, W. (2000). A series of progressive legal and ethical decision-making steps for using Christian spiritual interventions in psychotherapy. Journal of Psychology and Theology, $28,43-53$. 
Chamberlain, R. B. (1996). The use of spiritual interventions in psychotherapy: A qualitative study of Mormon therapists. Unpublished doctoral dissertation, Brigham Young University, Provo, UT.

Cook, T. H., \& Campbell, D. T. (1979). Quasi-experimentation. Chicago: Rand McNally College Publishing Company.

Crook-Lyon, R. E., O’Grady, K. A., Smith, T. B., Jensen, D. R., \& Golightly, T. (2007). Addressing religious and spiritual diversity in professional training: A survey regarding inclusion in multicultural education. Manuscript submitted for publication, Brigham Young University, Provo, UT.

Denzin, N. K., \& Lincoln, Y. S. (2000). Handbook of qualitative research $\left(2^{\text {nd }}\right.$ ed.). Thousand Oaks, CA: Sage.

Fowler, J. (1991). Stages in faith consciousness. In F. K. Oser \& W. G. Scarlett (Eds.), Religious development in childhood and adolescence [Special issue]. New Directions for Child Development, 52, 27-45.

Gorsuch, R. L. (1972). Single vs. multiple-item scales for measuring religious values. Journal for the Scientific Study of Religion, 11, 53-64.

Gorsuch, R. L. (1984). Measurement: The boon and bane of investigating religion. American Psychologist, 39, 228-236.

Griner, D., \& Smith, T. B. (2006). Culturally adapted mental health interventions: A metaanalytic review. Psychotherapy: Theory, Research, Practice \& Training, 43, 531-548.

Hage, S. M. (2006). A closer look at the role of spirituality in psychology training programs. Professional Psychology: Research and Practice, 37, 303-310.

Haug, I. E. (1998). Including a spiritual dimension in family therapy: Ethical considerations. Contemporary Family Therapy, 20, 181-194. 
Hawkins, I. L., \& Bullock, S. L. (1995). Informed consent and religious values: A neglected area of diversity. Psychotherapy, 32, 293-300.

Hoge, D. R. (1996). Religion in American: The demographics of belief and affiliation. In E. P. Shafranske (Ed.), Religion and the clinical practice of psychology (pp. 21-41). Washington, DC: American Psychological Association.

Hood, R. W., Jr., Spilka, B., Hunsberger, B., \& Gorsuch, R. (1996). The psychology of religion: An empirical approach ( $2^{\text {nd }}$ ed.). New York: Guilford Press.

Johnson, C. V., \& Hayes, J. A. (2003). Troubled spirits; Prevalence and predictors of religious and spiritual concerns among university students and counseling center clients. Journal of Counseling Psychology, 50, 409-419.

Jones, S. L., Watson, E. J., \& Wolfram, T. J. (1992). Results of the Rech conference survey on religious faith and professional psychology. Journal of Psychology and Theology, 20, 147-158.

Keller, R. R. (2000). Religious diversity in North America. In P.S. Richards and A. E. Bergin (Eds). Handbook of psychotherapy and religious diversity. Pp. 27-55. Washington, DC: American Psychological Association.

Kelly, E. W. (1995). Spirituality and religion in counseling and psychotherapy: Diversity in theory and practice. Alexandria, VA: American Counseling Association.

Koenig, H. G. (Ed.). (1998). Handbook of religion and mental health. San Diego, CA: Academic Press.

Lannert, J. L. (1991). Resistance and countertransference issues with spiritual and religious clients. Journal of Humanistic Psychology, 31, 68-76.

Miller, G. (2003). Incorporating spirituality in counseling and psychotherapy: Theory and technique. Hoboken, New Jersey: John Wiley \& Sons, Inc. 
Moon, G. W., Willis, D. E., Bailey, J. W., \& Kwasny, J. C. (1993). Self-reported use of Christian spiritual guidance techniques by Christian psychotherapists, pastoral counselors, and spiritual directors. Journal of Psychology and Christianity, 12, 24-37.

Nielsen, S. L., Johnson, W. B., \& Ridley, C. R. (2000). Religiously sensitive Rational Emotive Behavior Therapy: Theory, techniques, and brief excerpts from a case. Professional Psychology: Research and Practice, 31, 21-28.

Pargament, K. I. (1997). The psychology of religion and coping: Theory, research, and practice. New York: Guilford Press.

Poll, J., \& Smith, T. B. (2003). The spiritual self: Toward a conceptualization of spiritual identity development. Journal of Psychology and Theology, 31, 129-142.

Propst, L. R. (1980). The comparative efficacy of religious and nonreligious imagery for the treatment of mild depression in religious individuals. Cognitive Therapy and Research, 4, 167-178.

Propst, L. R., Ostrom, R., Watkins, P., Dean, T., \& Mashburn, D. (1992). Comparative efficacy of religious and non-religious cognitive-behavioral therapy for the treatment of clinical depression in religious individuals. Journal of Consulting and Clinical Psychology, 60, 94-103.

Richards, P. S. (1994). Religious devoutness, impression management, and personality functioning in college students. Journal of Research in Personality, 28, 14-26.

Richards, P. S., \& Bergin, A. E. (2005). A spiritual strategy for counseling and psychotherapy ( $2^{\text {nd }}$ ed.). Washington, DC: American Psychological Association.

Richards, P. S., \& Potts, R. W. (1995). Using spiritual interventions in psychotherapy: Practices, successes, failures, and ethical concerns of Mormon psychotherapists. Professional Psychology: Research and Practice, 26, 163-170. 
Richards, P. S., Keller, R., \& Smith, T. B. (2004). Religious and spiritual diversity in the practice of psychotherapy. In T. B. Smith (Ed.) Practicing multiculturalism: Affirming diversity in counseling and psychology. Pp. 276-293. Boston: Allyn \& Bacon.

Rizzuto, A. (1996). Psychoanalytic treatment and the religious person. In E. P. Shafranske (Ed.), Religion and the clinical practice of psychology (pp. 409-431). Washington, DC: American Psychological Association.

Rose, E. M., Westefeld, J. S., \& Ansley, T. A. (2001). Spiritual issues in counseling: Clients’ beliefs and preferences. Journal of Counseling Psychology, 48, 61-71.

Shafranske, E. P. (Ed.). (1996). Religion and the clinical practice of psychology. Washington, DC: American Psychological Association.

Shafranske, E. P. (2000). Beliefs and training of psychotherapists. In A. E. Kazdin (Ed.), Encyclopedia of psychology (Vol. 7, pp. 46-48). Washington, DC: American Psychological Association.

Shafranske, E. P., \& Malony, H. N. (1990). Clinical psychologists' religious and spiritual orientations and their practice of psychotherapy. Psychotherapy, 27, 72-78.

Smith, T. B., Bartz, J. D., \& Richards, P. S. (in press). Outcomes of religious and spiritual adaptations to psychotherapy: A meta-analytic review. Psychotherapy Research.

Smith, T. B., \& Richards, P. S. (2005). The integration of spiritual and religious issues in racial-cultural psychology and counseling. In R. T. Carter (Ed.): Handbook of racial-cultural psychology and counseling: Theory and research (vol. 1). Pp. 132-160. New York: Wiley.

Sonne, J. L. (1999). Multiple relationships: Does the new ethics code answer the right questions. In D. N. Bersoff (Ed.), Ethical conflicts in psychology (2n ed., pp. 227-230). Washington, DC: American Psychological Association. 
Sperry, L., \& Giblin, P. (1996). Marital and family therapy with religious persons. In E. P. Shafranske (Ed.), Religion and the clinical practice of psychology (pp. 511-532). Washington, DC: American Psychological Association.

Vaughan, F., Wittine, B., \& Walsh, R. (1996). Transpersonal psychology and the religious person. In E. P. Shafranske (Ed.), Religion and the clinical practice of psychology (pp. 483-509). Washington, DC: American Psychological Association.

Wade, N. G., Worthington, E. L., \&Vogel, D. L. (2007). Effectiveness of religiously tailored interventions in Christian therapy. Psychotherapy Research, 17, 91-105.

Walker, D. F., Gorsuch, R. L., \& Tan, S. (2004). Therapists’ integration of religion and spirituality in counseling: A meta-analysis. Counseling and Values, 49, 69-80.

Worthington, E. L. (1986). Religious counseling: A review of published empirical research. Journal of Counseling and Development, 64, 421-431.

Worthington, E. L., Jr., \& Sandage, S. J. (2002). Religion and spirituality. In J. C Norcross (Ed.), Psychotherapy relationships that work (pp. 383-399). New York: Oxford University Press.

Worthington, E. L., Jr., Dupont, P. D., Berry, J. T., \& Duncan, L. A. (1988). Christian therapists' and clients' perceptions of religious psychotherapy in private and agency settings. Journal of Psychology and Theology, 16, 282-293.

Young, J. S., Cashwell, C., \& Wiggins-Frame, M. (2007). Spirituality and counselor competencies: A national survey of American Counseling Association members. Journal of Counseling \& Development, 85, 47-52.

Young, J. S., Cashwell, C., Wiggins-Frame, M., \& Belaire, C. (2002). Spiritual and religious competencies: A national survey of CACREP-accredited programs. Counseling and Values, 47, 22-33. 
Table 1

Mean Ratings (and Standard Deviations) of and Correlations Between Client Ratings of Appropriateness and Helpfulness of Religious Interventions

\begin{tabular}{|c|c|c|c|c|c|c|}
\hline \multirow[t]{2}{*}{ Religious Interventions } & \multicolumn{2}{|c|}{$\begin{array}{l}\text { Appropriateness } \\
\text { Ratings }\end{array}$} & \multicolumn{3}{|c|}{ Helpfulness Ratings } & \multirow[b]{2}{*}{$r$} \\
\hline & $M$ & $S D$ & $M$ & $S D$ & $n$ & \\
\hline \multicolumn{7}{|l|}{$\underline{\text { In-session Interventions }}$} \\
\hline Reference to scripture & 3.76 & 1.0 & 3.65 & 1.3 & 63 & .35 \\
\hline Therapist private prayer & 3.69 & 1.2 & 1.91 & 1.9 & 11 & -.01 \\
\hline Teaching religious concepts & 3.47 & 1.2 & 3.97 & 1.2 & 73 & .49 \\
\hline Religious/spiritual self-disclosure & 3.32 & 1.3 & 3.77 & 1.5 & 47 & .61 \\
\hline Religious/spiritual assessment & 3.11 & 1.5 & 3.66 & 1.3 & 71 & .44 \\
\hline Religious/spiritual relaxation or imagery & 3.07 & 1.3 & 2.40 & 2.1 & 15 & .83 \\
\hline Religious/spiritual confrontation & 3.04 & 1.5 & 3.55 & 1.6 & 51 & .74 \\
\hline Therapist and client prayer & 2.70 & 1.5 & 1.44 & 1.9 & 9 & .69 \\
\hline Blessing by therapist & 1.99 & 1.5 & 2.00 & 2.4 & 11 & .65 \\
\hline Sum of in-session interventions & 28.3 & 8.0 & 31.5 & & & \\
\hline \multicolumn{7}{|l|}{$\underline{\text { Out-of-session Interventions }}$} \\
\hline Encouraging forgiveness of others & 4.26 & 1.0 & 3.70 & 1.4 & 50 & .37 \\
\hline Use religious community & 3.98 & 1.1 & 3.33 & 1.6 & 40 & .36 \\
\hline Religious/spiritual journaling & 3.95 & 1.0 & 2.58 & 1.8 & 19 & .17 \\
\hline Client prayer & 3.94 & 1.1 & 2.80 & 1.9 & 20 & .47 \\
\hline Religious/spiritual meditation & 3.83 & 1.2 & 3.10 & 1.9 & 21 & .29 \\
\hline Referral for blessing & 3.65 & 1.3 & 1.11 & 1.8 & 9 & .00 \\
\hline Religious bibliotherapy & 3.60 & 1.2 & 1.44 & 1.9 & 23 & .10 \\
\hline Encouraging client confession & 3.35 & 1.5 & 1.44 & 1.9 & 9 & -.18 \\
\hline Scripture memorization & 2.84 & 1.4 & 0.0 & 0.0 & 6 & -- \\
\hline Sum of out-of-session interventions & 33.7 & 8.6 & 26.5 & & & \\
\hline
\end{tabular}

NOTE: 146 participants provided appropriateness ratings (6 had missing data), but only clients who had experienced a particular intervention provided helpfulness ratings for that intervention ( $n$ 's indicated). 
Table 2

Qualitative Themes of Reasons Why Clients Perceived Spiritual Interventions to be Effective and Ineffective.

Effective $(n=78)$

Increased insight; reframed perceptions (47\%)

Increased personal comfort by sharing similar values with therapist (19\%)

Increased recognition of spiritual realities/influences (12\%)

Increased sense of empathy/connection from the therapist (8\%)

Increased credibility of therapy for clients initially skeptical (8\%)

Addressed client's “whole self” (6\%)

Ineffective $(n=37)$

Ineffective delivery of the spiritual intervention (32\%)

Increased feelings of anxiety or guilt (27\%)

Inappropriate therapist role to act as an ecclesiastical leader (22\%)

Inappropriate to include religious interventions in psychotherapy (19\%) 